In practice, I found that to krep the hlood at a proper tomperature by adding warm water to the basin in which the flask was immersed and stirring continually was tiring to the mures and time-wasting, necessitating the services of two pesple at least, sometimes more, since one became tired of holding the basin. Kernes ${ }^{2}$ in his excellent monograph gires no rery specific directions on this point, except that "the flask may be stood in a basin of warm water to keep it at borly tomperature." Inasmuch as, later on, he says that in certain cases-for example, of secondary anaemia, where there is a plethora of fluids"a half to three-guarters of an hour must be occupied in giving 500 c.cm. of blood" (with which I entirely agree) - that is, fortr-eight to seventy-two minutes for $800 \mathrm{c.cm}$. in a had case-anyone who has had experience of blood warming in this way will realize the extreme irksomeness of kecping the hasin at the right temperature for over an how, not to mention the shifting of the flask, with the risk, of bunping it against the basin-difficulties increased enormously in a prirate house.

Oswald Robertson," in the classical report on "Wound shock and Haemorrhage," coumenting on this point, remarks, "the bottle is restoppered and placed in a glass jar containing water at a temperature of $106^{\circ}-107^{\circ} \mathrm{F}$. $\left(41^{\circ}\right.$ C.). If the wator is maintained at this temperatirre, and the bottle is occasionally agitated, the blood becomes warm in a few minutes." True enough, but keeping it at an even temperature is almost impossible by mannal means with any degree of accuracy. It seemed to mo, therefore, high time that a thermostat should be used - that is, an automatically regulated water-bath, such as is used in the laboratory for Wassermamn tests, but adapted for this type of work.

\section{The Thermostat.}

With the collaboration of Messrs. Charles Hearson and (iv. T have erolved a convenient thermostat or water-bath, which is easily portable: it is smpported on a stand of the necesary rigidity and height. I collapsible stand has

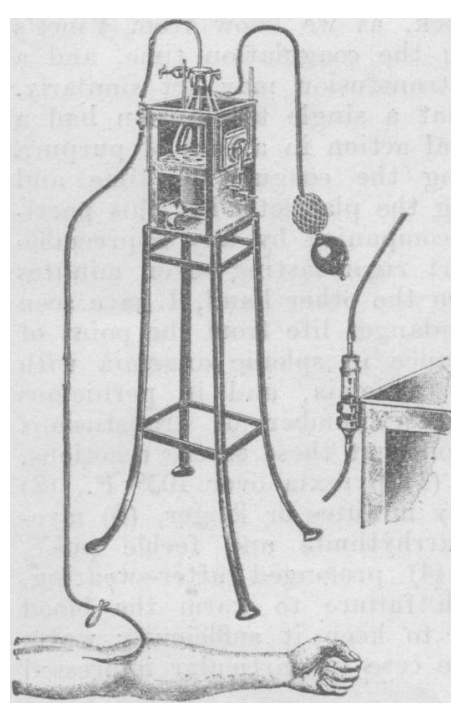
been, for the moment, ruled out, on account of the essential rigidity required. The stand can be introlinced into the average car for transport quite easily, and the trouble of taking it to the bedside is well repaid by the convenience of having an anchor and support of just the right height.

My mode of operation is as follows. The blood is drawn into one flask and filtered into another through several thicknesses of gauze. This filtration eliminates any minute clots, which rarely, hut dangerously, occur during even the best conducted bleedings. Meanwhile the thermostat has been wither lighted, or the current has been turned ou and the water warmed; it is a help to start with the apparatur half full of water at about the right temperature $\left(42^{\circ} \mathrm{C}\right.$. or $1070 \mathrm{~F}$.). The bath has a transparent window, which is turned towards the operator, so that he (an see the level of the blood. The flask is lightly clamped in, since otherwise it would rise up owing to buoyancy; the transfusion is not begun until the temperature remains constant at $42^{\circ} \mathrm{C}$., which takes a few minutes. This temperature allows two degrees drop during the transit of the blood down the tulse to the patient, and sufficient length of tubing is esscutial to (omfort in working. The bath is remarkably constant, the operation of the thermostat being excellent, whether for oil or electricity. Oil is crential for general purposes and for random transport, but for installation in one building electricity is proferable. If the whole apparatus is in noc when anaesthetics are being adminitered ta rery rare orcurvence, inasmuch as transfusions are usually given either before or after operations) (are must be taken to stand the apparatus well away from the head of the patient.

\section{Adrantages of having a Thermostat.}

1. One, if not two, assistants are dispensed with. The whole transfusion can be carried out maided if necessaly.

2. The blood is guarded from disturbance.

3. It arrives at the patient at the right temperature constantly throughout the transfusion, however long.

4. Reactions become negligible, assuming that the crosstest hus been carried out properly; cardiac reactions are abolished, pyrexia is reduced to practically nil, while rigors are rare or absent, and are very mild if present.

In my experience, the case for the transfusion thermostat is so obvious as to be incontrovertible.

The apparatus is supplied by Messrs. Charles Hearson and $c$. of 27, Mortimer Street, W.1, to whom I am indebted for muc help; and also by Messrs. Down Bros., St. Thomas's Street, s.E.1.

IVines, H. W. C. : Quart. Journ. Med., 1920, xiii, 257. 2 Keynes, F. Research Committe (now Council). Special Report Series, No. 25, p. 168.

\section{SEPTICAEMIA OF UNCOMNON ORIGIN. BY}

D. IVAN GRACEY, M.B., B.CH., LATE MEDICAL OFFTCER, MALAYAN MEDICAL SERVIEE.

Septrcakmis due to Bacillus pyocyaneus is of somewhat uncommon occurrence. Stitt ${ }^{1}$ states that this organism has until recently been considered rather harmless, but that this view can no longer be maintained, as it is frequently the sole cause of middle-ear inflammations, intestinal disorders, cystitis, and possibly at times of septicacmia. Park and Williams ${ }^{2}$ conclude that, althongì ordinarily but slightly pathogenic for man, it may, under certain conditions, "as in general debility, become a dangerous source of infection.

13. faecalis allialigenes is a normal inbabitant of the intestinal tract, and haematogenous infection due to this organism is rare. Stitt ${ }^{3}$ mentions that it has been isolated from a few cases which resembled typhoid fever. Castellani and Chalmers ${ }^{4}$ state that it may produce a fever resembling enteric, and that vaccines have been tried in a few cases, but no definite results have been obtained so far. His:Zinser and Russell ${ }^{5}$ quote a case of severe gastro-enteritis due to it, but add that it cannot be considered pathogenic: as a rule.

The following three cases, admitter to the Penang General Howpital, present some points of unusual interest.

CASE I.

A male Angio-Indian, aged 25, was admittrd on September 181h, 1529, with a history of irregular fever for six wecks; he liai been treated in another hospital for one month, but had left before he was well, and his condition had relapsed. His blool was there stated to be negative for malaria. On admission the temperature was $99.4^{\circ} \mathrm{F}$., and the pulse 90 . The heart and lungs wcre normal. The abdomen was flaccid, but showed no ditension, and the spleen was not palpable. A blood film was negative for malaria. The urine contained a faint trace of albumin and a few pus and epithelial cells. $B$. pyocyancus was grown. in pure culture from the blood in forty-eight hours, but cultures of the stools, urine, and sputum were found negative five days later. The Widal reaction was negative.

Cough and profuse expectoration of greenish malcrial occurred i wo lays after admission, accompanied by impairment of resonance and crepitations over the right lower lobe of the lung. There were no rigors, but the patient complained of feeling cold and shivery. Distension of the abdomen and enlargement of the spleen two fingerbreadths below the costal margin appeared on the fifth day, with serere epigastric pain. The pyrexia continued for thirty-two days before the temperature finally reached rormal, the highest point being $104^{\circ} \mathrm{F}$. Constipation was a troublesome feature. Intestinal antiseptics, such as salol and dimol, and colonic irrigations with sodium bicarbonate or yatren, at different periods, secmerl to have no influence on the course of the disease; quinine also hat no effect. Easton's syrup, given as a simple tonic when the temperature showed signs of abating, appeared to do some goa.t. The patient was discharged fit on November $71 !$.

\section{CASE II.}

A married Tamil woman, aged 26, was admittol on July $61 \mathrm{~h}$, 1929. with a hi-tory of fever and yomiting for three flas. and nain in the lower pant of the left side of the elost; she had hath 
amenorrhoea for six months. No cause could be found for the pain in the chest; the heart and lungs were normal, the abdomen showed no tenderness, and the spleen could not be felt. Tho temperature was $100.6^{\circ} \mathrm{F}$., and the pulse 100 . The blood was negative for malaria, and the urine containel a faint trace of albumin and some triple phosphates. The uterus reached just above the level of the umbilicus, and there was no vaginal discharge.

A premature male child, which only survived two hours and weighed $1 \mathrm{lb}$. $12 \mathrm{oz}$., was born five days later. The placenta and membranes were complete; the lochia were nerer offensive, and the uterus involuted normally. The temperature remained high, the pyrexia being sometimes continuous and sometimes intermittent. Rigors occurred at intervals. Metastatic abscesses formed in the right thigh and left side of the neck, and were inciserl. Pain was again felt in the lower part of the left side of the chest, accompanied by cough and expectoration. Dullness with diminution of the breath sounds was found, but this improved for a time with an expectorant mixture and the application of autiphlogistine.

On September 4th fluid was aspirated and found to be sterile on culture. A slight leucocytosis of 12,000 per c.mm. was present. Blood was withdrawn for culture on the same ciate, and $B$. faccalis "lkrtigcncs was isolated. Intravenous injections of neutral acriflavine and colloidal iodine were given, and some improvement in the temperature and general condition was noted but oul for a time. Two weeks later the patient's condition became much worse, the temperature rising to $105^{\circ} \mathrm{F}$; blood culture was repeated on September $27 \mathrm{th} ; B$. fuccalis cllkaligenes was again isolated and a vaccine prepared. The Widal reaction was negative. On October 16th a dose of one and a half million organisms was injected, followed after four days by a dose of two million. A moderately severe reaction occurred after the first injection, and definite improvement set in. The temperature subsided gradirally, and remained normal after the second injection. The patient asked to return home, and was discharged well on October $26 t h$.

\section{CASE III}

A male European planter, aged 22, was admitteal on July 21st, 1928, with a history of pain and swelling of the scrotum for four dars, accompanied by high fever; he strenuously denied any venereal infection. He liad had a swelling of the right knee one wosk previously due to an injury at football, and malaria in 1927. On examination intense tenderness and marked swelling of the right testicle was found, and, to a less extent, of the epididymis; the cord was much thickened and tender. There was no urethral discharge nor sore, and a prostatic examination was negative. 'The temperature was $102^{\circ} \mathrm{F}$., and the pulse 92 . Exanination of the blood and stools was negative. The urine was alkaline and contained triple phosphates, but was otherwise normal.

There was ccntinuous pyrexia, which subsided by lysis on the twenty-seventh day. An abscess of the testicle developed two weeks after admission, and was incised under general anaesthesia. 'The patient felt and looked remarkably well during the coursc of his ilmess, but headache, severe testicular rain, and obstinate constipation were all troublesome as regards treatment. Bimol and hexamine were administered, but did not $\mathrm{sem}$ to have any appreciable effect. When the temperature had subsided convalescence was uneventful, and the patient was discharged well on September $8 \mathrm{th}, 1928$

$\boldsymbol{\Lambda}$ direct smear from the urine showed no pus cells or gonococei, and culture for $\boldsymbol{B}$. coli communis was negative. Blood culture gave a fure growth of $\boldsymbol{B}$. faccalis allalig(niss on July $28 \mathrm{th}$, and the same organism was isolated in pure culture from the pus of the testicular abscess. The Widal reaction was positive to B. typhosus 1 in 200 on August 8th, and one week later showed a reduction in titre to 1 in 50 . As the patient had not been inoculated against enteric this may have been due to group agglutination. The Wassermann reaction was regative.

The infection in the first patient almost certainly had its origin in the intestinal canal, and was serere and prolonged for such an organism. The second case was interesting owing to its extremely lengthy course, the isolation of the organism concerned on two separate occasions at over three weeks' interval, and the remarkable response to vaccine treatment. Infection, evidentiy, had heen sustained prior to admission. In the case of the third patient the most striking feature was his excellent general condition throughout, in spite of a fairly severe infection. An opportunity was afforded of examining lim recently, and no atrophy of the testicle was found.

I have to thank Dr. H. O. Hopkins, Government Pathologist, Penang, who carried out the laboratory investigations.

\section{Referexces.}

1 Stitt: Practical Bacteriology, Blond Work, and Parnsitolm!!y. 19:7, 179. Stitt : Loc. (eit., 180 .

Stitt : Loc cit so. 180.

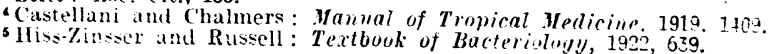

\section{Attemaranda :}

\section{MEDICAL, SURGICAL, OBSTETRICAL.}

\section{A POSSIBLE CASE OF PSITTACOSIS.}

Is riew of the recent outbreak of psittacosis the following (ase may be not without some interest.

On February 16th I was called to see a young woman, aged 32 , who had been taken ill five days previously with a rigor and a sudden tolinding headache, and went to bed. She was cxtremely prostrated, and romited several times. Hoping she would focl better, she rose on February 14th, but grew worse, and went to bed again. When I saw her she was very ill. She then had a short, dry, persistent cough, a headache which she described as agonizing, a sore mouth, the tongue covered with thick, brownisit fur, a slightly sore tl:roat, and complete anorexia. Her face was of a peculiar yellowish pallor, eres sunken and half shut, expression dull. The reflexes were sluggish. There had been no epistaxes, the spleen was not enlarged, and there were no adventitious sounds in the lungs. The abdomen was slightly distended; constipation was a prominent feature from the beginning, and she complained of a slight ache in the lumbar region. Insommia was very troublesome, and remained so until late in the illness. The urine showed nothing abnormal. The temperature was $103^{\circ} \mathrm{F}$., the pulse only 90 , and the respiration rate normal. The temperature, pulse, and respiration ratio remained practically constant throughout.

I suspected typhoid fever, and on making inquiries as to whether she was a contact $I$ found that she had been nursing enteric cases in Las Palmas for the past three years. She said she had only returned to England a fortnight previously, and added that she had been immunized against typhoid and paraiyphoid $A$ and $\mathbf{H}$ Further questioning elicited the information that during the royage home she had had a pet parrot in her cabin with her, and had fed and kept it clean herself. No mouth-to-beak feeding had taken place, but the bird used to perch on her shoulder; it was reported to be in good health. Agglutination tests for the colontyphoid group on February 17 th were negative in all dilutions. In view of the patient's statement about immunization, this was surprising, but it turned out that, as is common in Continental countries, she had taken the immunizing substance orally, this producing local immunity in the bowel only, and not forming agglutinins in the blood.

She grew steadily worse, was collapsed and weak, and intenscly depressed. On February 19th the headache was slightly better. but the patient was so weak that she could hardly move her head on the pillow, and she seemed slightly confused mentally, taking an apprcciable time before answering any question. On the same day she complained of a slight pain in the left side; the chest, however, was still clear, though the cough was as troublesome as ever, and the spleen was not palpable. On February 20th the headacho was better still, but she seemed even weaker, and had developed a mask-like facies. In the evening Dr. S. C. Dyke, honorary pathologist at the Royal Hospital, Wolverhampton, was kind enough to see her with me, and found a small, dull patch at the right apex, and some crepitations could be heard. Pain in the left side was now marked, but the spleen was still not palpable. He considered the case extremely suggestive of psittacosis, but as the bird, which had been left in Liverpool, was perfectly. healthy, and in view of the marked toxaemia and collapse, he suggested a possible apical pneumonia, and took blood to see if a count would confirm the finding. The white count was as follows, however, practically putting pneumonia out of court. Total white count: 9,100 per c.mm.; diffcrentirl count: polymorphs 65 per cent.; lymphocytes 29 per cent.; monocytes 5 per cent.; eosinophils, none seen; basophils 1 per cent.

On February 21st the headache had gone, the temperature was down to $99^{\circ} \mathbf{F}$., the dull patch at the right apex had decreased in- size, and the spleen was now palpable and very tencler. The improvement continued, the temperature falling by lysis, and by February 23rd the dull patch-at the right apex had disappeared, the cough, which had been unproductive throughout, became much better, and the spleen was no longer palpable, though there was still tenderness in the left side. Dr. Dyke saw the patient again on February 24th, and expressed the opinion that, clinically, it, was a clear-cut case of psittacosis, even though the parrot remained healthy. Agglutination tests repeated on February 27 th were again negative. The temperature was subnormal on March 3ril, and did not again rise above normal, but convalescence was longdrawn-out, and marked features were profound depression, a mask-like, Parkinsonian expression, and a persistence of the furring of the tongue till late on.

I regret that $I$ could not get permission to have the parrot in the case examined, but the yuestion arises. Is it possible for an apparently healthy bird to be a carier of the dicane? I understand that some surcess has follower the injection of the serum of persons lately inoculated with l.A.B. vareine, in cases of psittacosis, but 1 was unable 